\title{
POLÍTICAS PÚBLICAS, PLANEJAMENTO URBANO E A PRODUÇÃO DO ESPAÇO EM BOA VISTA-RR
}

\author{
PUBLIC POLICIES, URBAN PLANNING AND THE \\ PRODUCTION OF SPACE IN BOA VISTA-RR
}

\author{
POLÍTICAS PÚBLICAS, PLANEAMIENTO URBANO Y LA \\ PRODUCCIÓN DEL ESPACIO EN BUENA VISTA-RR
}

\author{
Amarildo Nogueira Batista - Universidade Estadual de Roraima - Boa Vista - Roraima - Brasil \\ (In memoriam; falecido em 14 de julho de 2017)
}

\author{
José Borzacchiello da Silva - Universidade Federal do Ceará - Fortaleza - Ceará - Brasil \\ borzajse@gmail.com
}

\section{Resumo}

Boa Vista, capital do estado de Roraima, no que tange ao processo de produção de seu espaço urbano, não foge à regra e expressa o que ocorre na Amazônia brasileira, que pode ser analisado como reflexo da ação dos agentes produtores do espaço na proposição e na implementação de políticas públicas. 0 presente artigo discute a produção do espaço urbano de Boa Vista a partir da inserção de políticas públicas urbanas no período de 1988, ano da criação do estado de Roraima. 0 texto aborda aspectos teóricos e empíricos, elementos constitutivos da pesquisa realizada, tais como planejamento, políticas públicas e produção do espaço. A opção pelo método analítico-sintético possibilitou a reflexão sobre 0 urbano, tendo como base de apoio pesquisas bibliográficas, documentais e trabalho de campo, além de visitas a diferentes órgãos de gestão. A indagação motivadora da pesquisa perguntava quais eram os principais agentes promotores do espaço urbano, bem como quais eram as políticas públicas implantadas a partir de 1988. Para dar fecho ao período pesquisado, buscou-se compreender como as políticas públicas interferiram na organização do processo de produção do espaço urbano da cidade.

Palavras-chave: Gestão, produção do espaço, políticas públicas, Boa Vista.

\section{Abstract}

Boa Vista capital of the state of Roraima in relation to the production process of its urban space does not escape the rule and expresses what occurs in the Brazilian Amazon that can be analyzed as a reflection of the action of the producers of space in the proposal and implementation of public policies. This article discusses the production of the urban space of Boa Vista from the insertion of urban public policies in the period of 1988 , the year of the creation of the State of Roraima. The text addresses theoretical and empirical aspects, constitutive elements of the research carried out such as Planning, Public Policies and Space Production. The option of the analytical-synthetic method made possible the reflection on the urban, based on bibliographical research, documentaries and fieldwork, as well as visits to different management bodies. The motivating question of the research asked which were the main agents of the urban space, as well as the public policies implemented since 1988? In order to close the period studied, it was sought to understand how the public policies interfered in the organization in the process of production of the urban space of the city. Keywords: Management, production of space, public policy, Boa Vista. 


\section{Resumen}

Sobre el proceso de producción de su espacio urbano Boa Vista, capital del estado de Roraima, no escapa a la regla y expresa lo que ocurre en la Amazonía brasileña, que puede ser analizado como un reflejo de la acción de los productores de espacio en la propuesta y la implementación de las políticas públicas. Este artículo discute la producción del espacio urbano en Boa Vista desde el inserción de políticas públicas urbanas en el período de 1988, año en que se creó el Estado de Roraima. El texto aborda aspectos teóricos y empíricos, elementos constitutivos de la investigación que Incluye Planificación, Políticas Públicas y Producción de Espacio. La opción del método analítico sintético permitió la reflexión sobre lo urbano, en base bibliográfica y documental investigación y trabajo de campo, así como visitas a diferentes órganos de gestión. La pregunta motivadora la investigación preguntó cuáles eran los principales agentes del espacio urbano, así como las políticas públicas implementado desde 1988. Para cerrar el período estudiado, el objetivo era comprender cómo las políticas públicas interfirieron en la organización del proceso de producción del espacio urbano de la ciudad.

Palabras clave: gestión, producción de espacio, políticas públicas, Boa Vista.

\section{Gestão e planejamento urbano e a produção do espaço}

Gestão e planejamento urbano são aspectos imprescindíveis para a compreensão da organização de uma cidade. Eles contribuem para entender como são ou foram orientadas as políticas para um determinado espaço e permitem análises dos processos recorrentes à produção do espaço urbano em um determinado tempo. Segundo Silva (2008, p. 84):

O planejamento urbano emerge como solução para todos os problemas na cidade. Elaborado e aperfeiçoado a partir do avanço da ciência e das novas conquistas tecnológicas do século XVIII, logo de início, assume papel ímpar no processo de ordenamento e gestão do território, tornando-se verdadeiro instrumento disciplinador do governo no exercício da gestão urbana.

No caso brasileiro, a compreensão da gestão e do planejamento urbano exigiu maior reflexão e análise das bases históricas explicativas dos elementos constituintes do processo de urbanização do país, especialmente a partir dos anos 50 do século XX. Nesse sentido, deve-se considerar o momento de transição da economia agroexportadora para a industrial, quando o planejamento é concebido e praticado como um recurso tecnocrático de desenvolvimento social e econômico e as políticas públicas são implementadas como vetor do progresso.

A elaboração de políticas públicas de uma determinada gestão é conduzida por intencionalidades, sendo que, nesse processo, as classes mais beneficiadas são aquelas que detêm o controle político-administrativo, geralmente as proprietárias do capital. Assim, gestão e planejamento não são ações aleatórias, mas direcionadas por aqueles que detêm o poder do capital e que controlam o Estado (Souza, 2006). 
Vê-se, assim, que as políticas públicas, longe de serem neutras, tornam-se ferramentas de controle espacial, social e econômico em diferentes contextos espaciais, seja uma pequena localidade, um bairro, seja uma zona ou região. Através delas, ocorre a participação de grupos sociais excluídos, que podem exigir direitos e garantias em consonância com o aparato legal disposto na Constituição.

O planejamento concebido como política pública torna-se um instrumento fundamental na regulação do processo de produção do espaço. Por sua vez, mostra que o modelo tradicional de planejamento, baseado em regras, regulamentos, hierarquias, centralização e autoritarismo, não permite participação dos diferentes agentes sociais. É controversa a concepção de ser o Estado o único ente público em condição de conceber e executar as políticas públicas, pois alimenta o pressuposto da incapacidade de atender todas as demandas (Souza, 2004)

Nesse sentido, o planejamento urbano é uma força que vai para além das simples definições empíricas de localizações de áreas, arruamentos e ajardinamento. Ele deve ser um instrumento de garantias sociais, como preceitua o Estatuto da Cidade, que, para Silva (2011),

é o caminho mais adequado para responder às demandas sociais. Para efetivá-lo, é fundamental assegurar a justa distribuição dos benefícios e ônus do processo de urbanização. Sua concretização depende de fatores diversos, entre os quais se destaca o amplo engajamento da sociedade com o interesse social.

O Estatuto da Cidade é instrumento fundamental no estabelecimento de políticas públicas e no processo de produção do espaço.

Santos (2002 p. 63) explicita que o espaço geográfico é "formado por um conjunto indissociável, solidário e também contraditório, de sistemas de objetos e sistemas de ações, não considerados isoladamente, mas como o quadro único no qual a história se dá”. No processo de produção do espaço, a natureza provê as 'coisas', as quais são transformadas em objetos pela ação do homem por meio de técnicas e processos.

O espaço analisado enquanto produto contém em seu processo um movimento articulado entre as forças políticas e ideológicas num processo contingente, com resultados contenciosos envolvendo estrutura e ação, que são "engendradas por agentes que produzem e consomem espaço", conforme afirma Gottidiener (1993). Para Corrêa (2000, p. 11), "São agentes sociais 
concretos, e não um mercado invisível ou processos aleatórios atuando sobre um espaço abstrato".

Assim, se o espaço urbano for considerado como produto social, reconhece-se que ele é resultado da produção dos atores que o produzem e o consomem intencionalmente. A ação destes agentes deriva da dinâmica de acumulação de capital, das necessidades de reprodução das relações de produção e dos conflitos de classe que dela emergem. Ao mesmo tempo, está relacionada ao jogo de poder e de interesses entre os diferentes agentes, fruto das relações travadas entre estes, que resulta em objetos que podem não atender a todos e, consequentemente, gerar segregação e deterioração de áreas em processo de ocupação.

\section{Histórico da ocupação do planejamento urbano amazônico}

Batista (2013, p. 60) argumenta que

a produção do espaço amazônico, no qual Boa Vista se insere, historicamente é marcado pela expropriação fundiária, o autoritarismo na gestão das políticas públicas e a proeminência do Estado como principal promotor do espaço, degradação ambiental e conflitos etno-raciais, entre outros.

Dia ainda que "é fundamental conhecer os processos históricos e espaciais que foram sendo produzidos para captar que elementos que influenciaram na dinâmica amazônica e que vão influir na estruturação das cidades" (Quadro 1). 
Quadro 1 - Evolução da estruturação urbana na Amazônia (1850-2005)

\begin{tabular}{|c|l|l|}
\hline PERÍODO & \multicolumn{1}{|c|}{ CONDICIONANTE } & \multicolumn{1}{|c|}{ ESTRUTURA URBANA DECORRENTE } \\
\hline Séc. XVIII -1850 & Missões & $\begin{array}{l}\text { Formação de vilas nas várzeas do Amazonas } \\
\text { e afluentes por missionários, índios e colonos }\end{array}$ \\
\hline $1851-1891$ & Exploração da borracha & Forma dendrítica da rede Proto-Amazônia \\
\hline $1892-1912$ & Apogeu da borracha & Estrutura urbana Primaz-Belém \\
\hline $1913-1965$ & Declínio da borracha & Estagnação local e primazia de Manaus \\
\hline $1966-1985$ & Intervenção do Estado & Grandes projetos de ocupação regional \\
\hline $1991-1996$ & Migrações localizadas e pouco expressivas & Macrozoneamento regional \\
\hline $1997-2000$ & $\begin{array}{l}\text { Descentralização do Estado } \\
\text { 2001-2005 }\end{array}$ & $\begin{array}{l}\text { Interligação das cidades com a rede urbana } \\
\text { nacional e internacional }\end{array}$ \\
\hline $2006-2015$ & $\begin{array}{l}\text { Novos ciclos de migração nacional } \\
\text { internacional. Expansão comercial } \\
\text { ampliação de postos de trabalho }\end{array}$ & Expansão urbana \\
\hline
\end{tabular}

Fonte: Elaborado pelos autores (2016) e adaptado de Batista, Amarildo Nogueira. Políticas públicas e produção do espaço urbano de Boa Vista (1988/2011), 2013. Dissertação (Mestrado) - Programa de Pósgraduação de Geografia da Universidade Federal de Rondônia, Boa Vista, p. 61, e dados do MTC (2000).

Batista (2013, p.61) afirma que, "ao longo da história da produção espacial na Amazônia, percebe-se que uma das estratégias utilizadas pelo governo brasileiro para o desenvolvimento da região foi, em 1850, a concessão do uso de navegação a investidores privados, para o transporte de mercadorias".

A partir de meados do século XX, com a definição dos limites fronteiriços da Amazônia brasileira, ocorre também a chamada "Marcha para Oeste”, que representava a integração da insular Amazônia ao Sudeste. Esse processo representou a efetivação da ocupação da região e, ao mesmo tempo, a degradação do homem, do meio social e natural no processo de busca pelo crescimento econômico regional (Huerta, 2009).

O processo de ocupação se acirrou a partir da metade de 1960, com os grandes projetos desenvolvidos pelos governos militares, os quais exerceram influência na urbanização da Amazônia. Na década seguinte, foi produzida uma série de ações que visam à integração da Amazônia ao Sudeste. Essas políticas tinham por meta implantar infraestrutura, 
transportes, comunicação e centros urbanos, no sentido de garantir a consolidação econômica e a segurança nacional e resolver as tensões agrárias ocorridas no Nordeste. Destaca-se, assim, o Estado operando no domínio territorial (Quadro2).

Quadro 2 - Processo de formação da cidade de Boa Vista-RR (1890-2011)

\begin{tabular}{|l|l|l|}
\hline PERÍODO & CONDICIONANTE & \multicolumn{1}{c|}{ CARACTERIZAÇÃo } \\
\hline $1890-1920$ & A formação & Formação da freguesia, vilas e povoados \\
\hline $1921-1940$ & A consolidação & Consolidação de Boa Vista, como cidade central, macrocefálica \\
\hline $1941-1960$ & O plano urbanístico & Implantação do plano urbanístico (radial-concêntrico) \\
\hline $1961-1980$ & A expansão & A expansão para além do plano urbanístico \\
\hline $1981-2000$ & A nova expansão & A expansão no setor oeste da cidade \\
\hline $2001-2011$ & Reurbanização & Desenvolvimento de políticas de urbanização \\
\hline $2012 ~ 2015$ & $\begin{array}{l}\text { Migrações e } \\
\text { negócios }\end{array}$ & $\begin{array}{l}\text { Nova expansão urbana com conjuntos habitacionais, concursos } \\
\text { públicos e empreendimentos comerciais e agrícolas }\end{array}$ \\
\hline
\end{tabular}

Fonte: Elaborado pelos autores (2016) e adaptado de Batista, Amarildo Nogueira. Políticas públicas e produção do espaço urbano de Boa Vista (1988/2011), 2013. Dissertação (Mestrado) - Programa de Pósgraduação de Geografia da Universidade Federal de Rondônia, Boa Vista, p. 61, e dados do MTC (2000).

Batista (2013, p. 65) recupera aspectos relevantes quanto às bases do povoamento, à origem e ao crescimento de Roraima. Foi o Decreto-lei Federal $n^{\circ}$. 5812, promulgado em 13 de setembro de 1943 e retificado pelo Decreto-lei no 5839 do mesmo mês e ano, que criou o Território Federal do Rio Branco, o qual, posteriormente, conforme o Decreto-lei $\mathrm{n}^{\circ}$. 4.182, de 13 de setembro de 1962, teve seu nome alterado para Território Federal de Roraima, devido às constantes confusões e ao extravio de correspondência e mercadorias que eram enviadas para a cidade de Rio Branco, capital do Acre.

A criação do território federal foi fundamental no processo de ocupação dessa porção setentrional do Brasil. A criação de novos postos de trabalho e a expansão de áreas de agricultura e de pecuária provocaram a transferência de colonos de outras regiões do país, que vinham em busca de novas oportunidades.

Quanto à dinâmica da capital do novo território, Batista (2013, p. 67) é enfático ao afirmar que 
O processo de formação de Boa Vista-RR tem suas particularidades, mas deve ser compreendido dentro da produção do espaço regional amazônico que seguiu a estratégia de integração ao capitalismo nacional e internacional iniciado na região com o ciclo da borracha (1850-1911).

Prosseguindo, o autor, apoiado em Barros (1995) e Freitas (1997), mostra que "essa atividade foi a principal fonte de geração de capital e atrativo para os primeiros migrantes oriundos do Nordeste. Para entender os aspectos históricos e espaciais presentes na cidade, "essa atividade foi a principal fonte de geração de capital e atrativo para os primeiros migrantes oriundos do Nordeste “ (p. 65).

A dinâmica demográfica do antigo território transformado em estado da federação em 1988 e, especialmente, o crescimento de sua capital são explicados por Silva (2007, p.57), segundo quem,

é necessário compreender os processos que antecederam o que veio a ser a cidade de Boa Vista-Roraima, iniciados com a edificação do Forte de São Joaquim, entre 1775 e 1778, a implantação dos Aldeamentos Indígenas, das Fazendas Reais: São Bento, São José e São Marcos, no final do século XVIII, a criação da Fazenda Boa Vista em 1830, e da Freguesia de Nossa Senhora do Carmo, em 1858, por meio da Lei Provincial n ${ }^{\circ} 092$ que historicamente é um dos primeiros momentos na edificação administrativa-política da região.

Emancipada em 1890, a Vila de Boa Vista do Rio Branco, um pequeno aglomerado aparentemente inexpressivo, fincava as bases do que viria ser a futura cidade. $\mathrm{O}$ barro e a palha eram dominantes em suas construções, revelando a precariedade das condições de vida dos que se aventuravam naquela porção do território brasileiro e que se ocupavam com atividades ligadas ao setor primário, sendo a atividade principal a criação de gado bovino e a agricultura de subsistência.

Mostrando a rápida dinâmica da cidade com uma nova configuração de sua planta, Batista (2013, p. 66) diz que:

Na década de 1920, quando se iniciou um processo primário do dimensionamento urbano do que viria a ser a capital de Roraima, já era perceptível novos arranjos urbanos com a construção de ruas, prédios públicos e privados e casas, organizados dentro de um modelo octogonal, tabuleiro, que veio a ser aperfeiçoado 20 anos após para o modelo radial-concêntrico (Figura 1). 


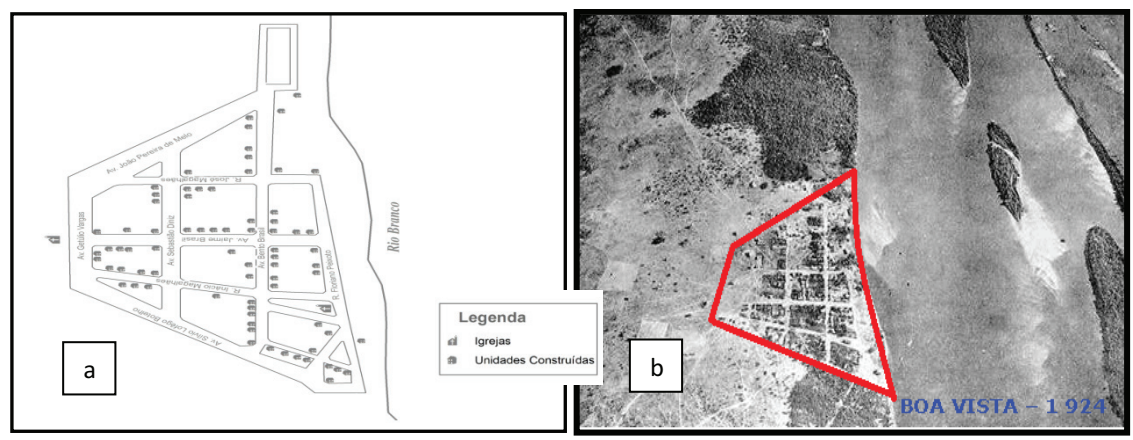

Figura 1 - Croqui da cidade de Boa Vista (1924) e foto aérea de Boa Vista em 1924

Fonte: (a) Território Federal de Roraima (1987)/(b) Modificado pelo autor em 2012 de Rice (1978).

Aprofundando a explicação sobre o processo de produção do espaço amazônico, Batista (2013, p. 67) observa que o governo do presidente Getúlio Vargas (1930-1945) e os governos militares (1966-1985), preocupados com as amplas fronteiras e com a ideia de "vazio geográfico", implantaram um conjunto de estratégias no sentido de promover o crescimento econômico e a ocupação física da Região Amazônica.

Outro aspecto foi a mudança urbanística. Seu formato de tabuleiro, datado de 1924, 20 anos depois foi alterado para o formato de leque, conforme o projeto do engenheiro civil Darcy Aleixo Derenusson. O modelo proposto tinha como base a cidade de Belo Horizonte, em Minas Gerais. As obras foram executadas pela firma carioca Riobras, de propriedade do referido engenheiro (Figura 2).

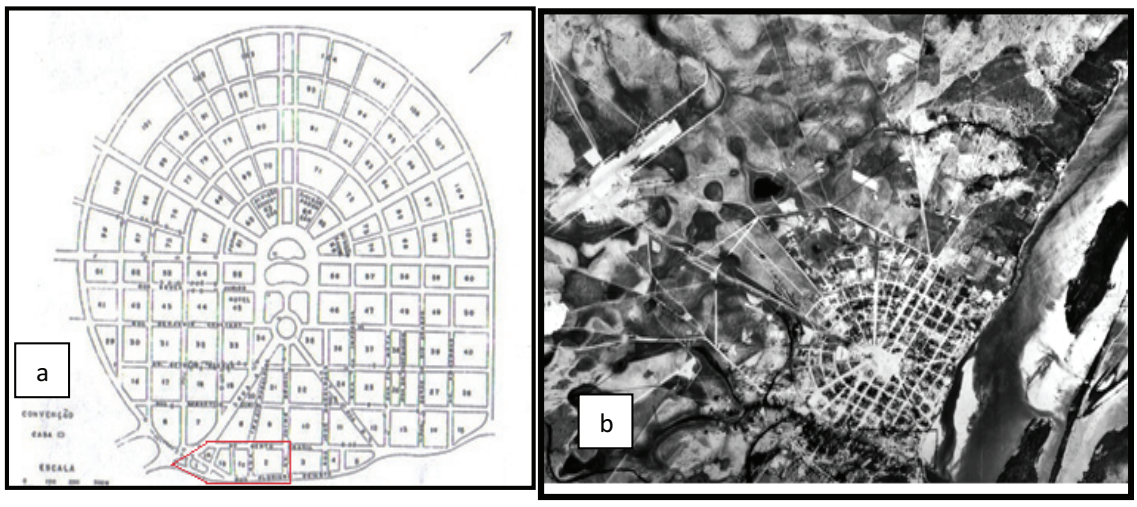

Figura 2 - Plano radial-concêntrico de Boa Vista (1946) e imagem de Boa Vista (1969) Fonte: (a) e (b) Modificado pelo autor 2012, de Veras (2011). 
Esse modelo urbanístico radial-concêntrico, da década de 1940, foi implantado logo após a criação do Território Federal do Rio Branco, quando o governo federal passou a definir políticas de desenvolvimento urbano para a Amazônia. Representou o ideário de modernização do território.

Nesse sentido, o processo de crescimento urbano da cidade se deu de modo lento, uma vez que as políticas de investimentos locais eram escassas, ou seja, era visível a ausência de um ordenamento territorial local, isto é, de uma infraestrutura urbana que contribuísse para a qualidade de vida dos citadinos (Veras, 2009).

Contudo, nos anos 1970, dado o crescimento urbano para além da antiga área central planejada em 1946, não se podia mais responder às alterações ocorridas na morfologia urbana da cidade. Assim, se percebe que o modelo formalista, radial-concêntrico, passa a ser acrescido de outro, amorfo, constituindo a base de ocupações irregulares e especulações imobiliárias.

É importante destacar que o crescimento populacional e urbano ocorrido na década de 1970 foi influenciado pelas atividades do garimpo, da construção civil, da implantação de novos órgãos da administração pública e militar e dos empreendimentos agrícolas, emanados dos projetos de ocupação e desenvolvimento da Amazônia.

Silva (2007) e Becker (1998, p. 46), este quando afirma que "a fronteira atual já nasce urbana, como uma estratégia de ocupação utilizada pelo Estado", mostram que o planejamento de Boa Vista - RR, implantado a partir dos anos de 1950, está presente no projeto geopolítico nacional de ocupação da Amazônia, que tinha por meta ocupar e povoar essa região.

A expansão urbana, a partir de 1985, foi influenciada pelas políticas assistencialistas dos governos Ottomar de Souza Pinto (1979-1983) e (19911995) e Romero Jucá Filho (1987-1989), que estimularam o surgimento de novos bairros por meio de políticas de incentivo migratório para áreas rurais e urbanas e da distribuição de lotes urbanos (Silva, 2007; Veras, 2009).

Batista, apud Silva (2007), destaca que, no ano de 1988, a capital já apresentava um total de 25 bairros e estava em franco crescimento, influenciado pelo garimpo, pelas vagas em setores administrativos no recém-criado estado e pela expansão das atividades comerciais e agrícolas, ações alavancadas pelos projetos de desenvolvimento da Amazônia. 
Pode-se considerar que a mobilidade provocada por esses projetos provocou mudanças na configuração urbana e regional.

Luckmann (1989), ao criticar o modelo de ocupação, diz ter sido ele o responsável pelo crescimento desordenado, principalmente para além da área de abrangência do plano urbanístico. Destaca os problemas de infraestrutura urbana, pois os bairros eram criados atendendo a critérios políticos, por meio da distribuição não ordenada dos lotes, seguindo a lógica de primeiro ocupar e depois estruturar (Veras, 2009).

Prejudicadas por ações governistas e eleitoreiras, as normas estabelecidas pelas políticas urbanas planejadas não eram obedecidas. A cidade crescia sem ordenamento, a despeito dos parâmetros urbanísticos traçados em seus planos. Esse crescimento urbano, notadamente entre 1980 e 1990, dará origem à formação de novos bairros (Figura 3).

O garimpo atrai milhares de forasteiros para Roraima. Chegam pelo aeroporto de Boa Vista, buscam as áreas de exploração e fazem da cidade a base de sustentação de suas atividades. De acordo com Barbosa (1993, p.187), a descoberta de ouro e diamante ocasionou "um fluxo de garimpeiros das zonas de garimpo para a cidade que, sem motivação de retornar à terra natal ou completamente descapitalizado para fazê-lo, veio a engrossar as fileiras de pobreza na periferia da cidade". 


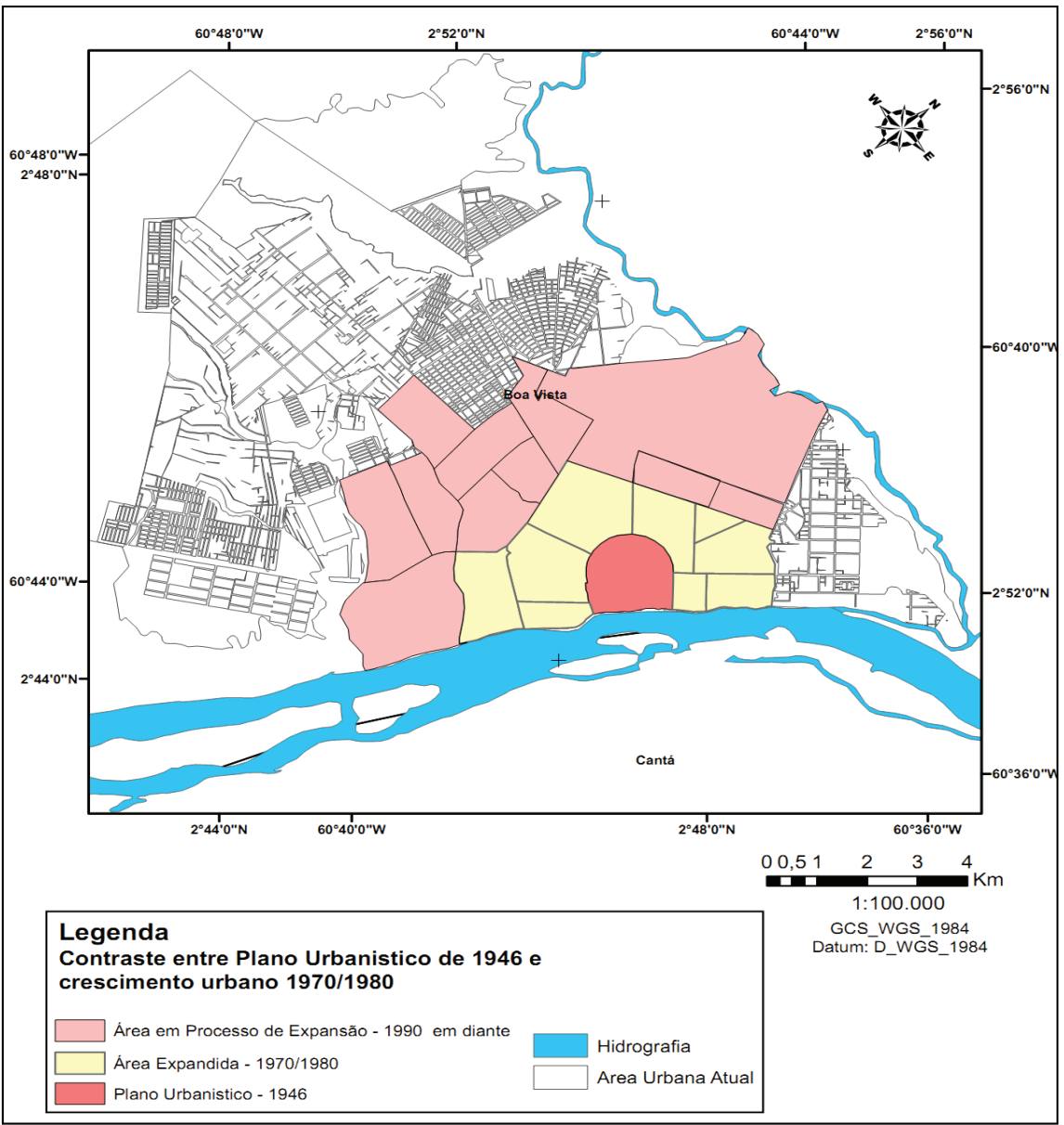

Figura 3 - Contraste entre o Plano Urbanístico de 1946 e o crescimento urbano Fonte: Elaborado pelos autores, 2016.

A propósito do garimpo, cabe destacar que, do mesmo modo que ocorreu a vinda de garimpeiros para a área urbana de Boa Vista em 1990, provocando aumento da população, constata-se também um movimento contrário, uma vez que a atividade garimpeira havia sido proibida em Roraima e muitos forasteiros retornaram para seus estados de origem (Barros, 1995) 
Quando do fechamento dos garimpos em Roraima, era muito forte a ingerência do governo do Estado sobre as políticas públicas adotadas para a capital. Nesse período, em face do número expressivo de famílias que permaneceram em Boa Vista, o governo adota a política de doação de lotes urbanos, ampliando a malha urbana da cidade. Bonatto (2002) e Barros (1995) destacam que um exemplo disso foram as políticas assistencialistas de distribuição de cestas básicas de alimentação e a apressada distribuição de lotes urbanos nas áreas periféricas, sem a infraestrutura adequada.

Segundo Batista (2013, p. 73), "Essas ações na verdade tinham fins eleitoreiros”. Barbosa (1993a, p. 33) afirma que o primeiro governador eleito do estado de Roraima, o brigadeiro Ottomar de Souza Pinto (1991 a 1994), declarou "o desejo de assentar 50.000 famílias em todo o Estado. [...] a notícia tornou-se um incentivo indireto para [...] migração em direção a Roraima”. Na esperança de receber um lote de terra agrícola, esse tipo de política de governo contribuiu para o aumento populacional e o crescimento urbano de Boa Vista, cidade que concentra um elevado percentual da população do estado.

Políticas públicas urbanas de Boa Vista-Roraima (1988-2011)

Boa Vista, capital do estado de Roraima, objeto da presente pesquisa, localiza-se à margem direita do Rio Branco, no Hemisfério Norte, sob as seguintes coordenadas geográficas: Latitude $2^{\circ} 45^{\prime} 11^{\prime \prime} \mathrm{N}$ e Longitude $60^{\circ} 39^{\prime} 0^{\prime \prime}$ Oeste de Greenwich. A cidade integra a Amazônia setentrional, e sua área municipal está situada totalmente no Hemisfério Norte. O município ocupa uma área de $5.687 \mathrm{Km}^{2}$ e não tem fronteira com os países vizinhos da Venezuela e da Guiana (IBGE,2011 2010) (Figura 4). 

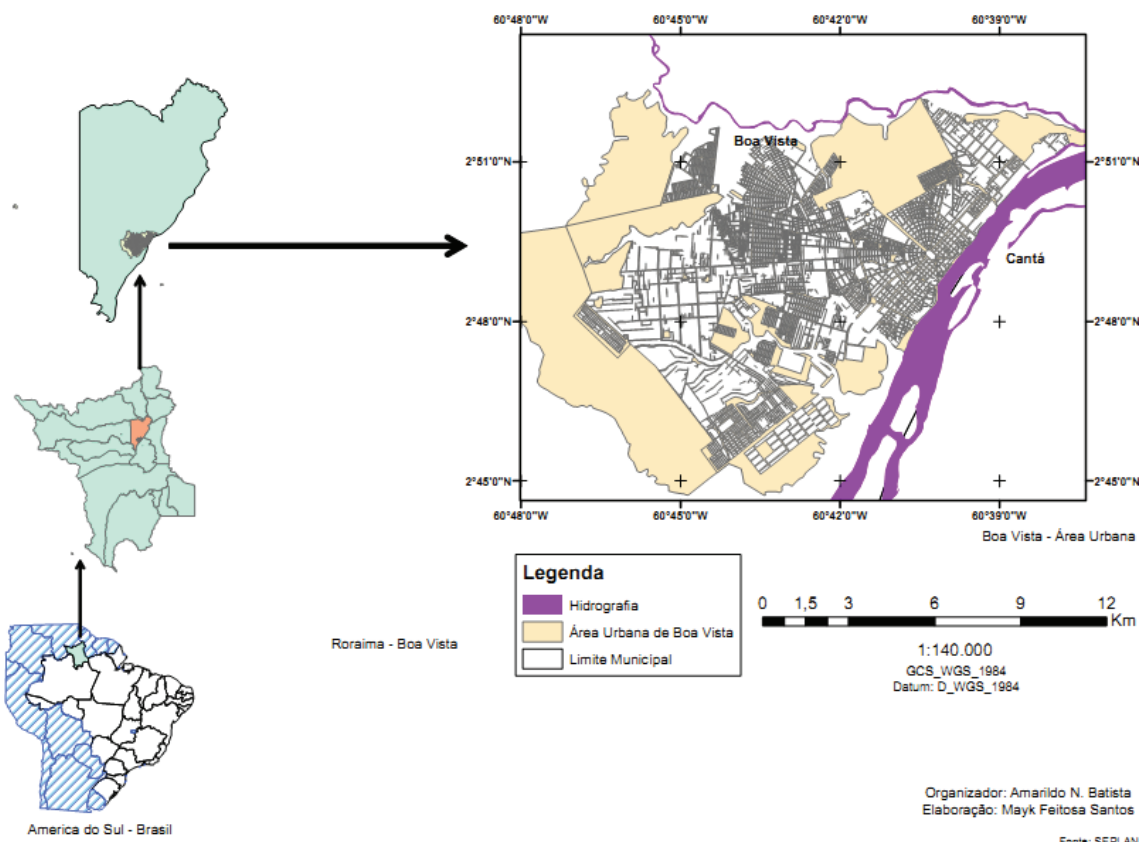

Figura 4 - Mapa de localização da cidade de Boa Vista

Fonte: Batista (2013).

Barac da Silva Bento, doravante Barac Bento, implantou a administração da prefeitura, criando diversos órgãos. Antes, era o governo do território que controlava a política urbana do município da capital. Em 1989, firmou contrato com a prefeitura de Curitiba, através do Instituto de Pesquisa Urbana de Curitiba, para elaborar um plano diretor para a cidade de Boa Vista (Veras, 2009, p.164).

Durante a década de 1990, Boa Vista não se diferenciava de outras cidades brasileiras de seu porte, embora exercesse expressivo peso funcional como capital do recém-criado estado de Roraima. Cabe destacar sua importância, considerando sua localização nesta porção da Amazônia setentrional, onde estendia sua ação, atendendo às demandas do capital industrial e comercial. O estabelecimento de diretrizes para seu crescimento urbano se dá nesse período, com a elaboração e a implantação do Plano Diretor Desenvolvimento Urbano/Boa Vista - RR, pela Lei $\mathrm{n}^{\circ}$ 244, de 6 de setembro de 1991. As proposições desse instrumento de 
orientação e organização do espaço urbano da cidade foram fundamentais no disciplinamento e na organização urbana da capital. Com ele, foram estabelecidos os limites dos bairros existentes, e novos bairros foram acrescentados, num total de 18. Essas mudanças foram fundamentais para a adoção de políticas públicas, considerando a alteração da trama urbana com as orientações do sistema viário, consolidando áreas mais densas e criando condições, mesmo que em pequena escala, de organizar as demais áreas passíveis de expansão.

O plano, entretanto, contrariando suas proposições, apesar dos estudos e levantamentos preliminares, não foi capaz de ordenar o crescimento da cidade, especialmente nas áreas urbanas de expansão recente. A não obediência às normas estabelecidos pelo Plano Diretor, no tocante ao uso e à ocupação adequados do espaços urbanos, contribuiu para piorar as condições de vida das populações dos novos bairros instalados em áreas periféricas da capital.

Batista (2013. p. 86) assim descreve esse momento do planejamento urbano em Boa Vista: "Observa-se o espaço de poder, devidamente pensado dentro das concepções liberais de uso e consumo do espaço, como as áreas de expansão induzidas para o setor Oeste, onde atualmente está o maior número de habitantes, e consequentemente os trabalhadores”. O que é confirmado por vários autores, dentre eles Maricato (1997), que é enfática quando refere-se aos planejamentos produzidos dentro da prática liberal, dizendo que eles são construídos para atender às necessidades do capital e de sua manutenção.

Discutindo o período da gestão de Barac Bento, Batista (2013, p. 86) diz que "devido à política de financiamento habitacional, ocorreu uma eclosão de conjuntos habitacionais, inicialmente construídos por empresas contratadas. Esses conjuntos integravam a política do Governo Federal, como forma de superar o déficit habitacional".

Em Boa Vista, essa política utilizada para fins eleitoreiros alterou sobremaneira os setores Oeste e Sul da cidade. Os novos bairros que surgiam nos setores Oeste e Sul caracterizavam-se por ocupações irregulares que apresentavam quadro de carência e escassez de infraestrutura física, de equipamentos e serviços essenciais (água, luz, telecomunicação, saneamento, pavimentação, coleta de lixo, transporte), social (educação, saúde, segurança, lazer), além de degradação ambiental. O dinamismo da cidade revelava um quadro contraditório, caracterizado, 
por um lado, pelo crescimento demográfico e pelo aumento da malha urbana e, por outro, pela insuficiência de políticas urbanas capazes de atender às demandas populares em função desse crescimento. Ficava evidente a dissonância entre a prática da gestão urbana e o pressuposto do planejamento, que mostrava-se incapaz de responder às demandas sociais dos setores mais carentes da cidade.

Maria Teresa Saenz Surita, doravante Teresa Surita, durante os períodos em que foi prefeita de Boa Vista, conduziu a política urbana de sua gestão para obras de urbanização, drenagem, iluminação pública, produção de diagnósticos da cidade e projetos sociais. Governou a capital nos períodos de 1993 a 1996, de 2001 a 2004 e de 2005 a 2008. No último período de sua gestão, abriu mão do cargo para concorrer a uma vaga no Senado Federal.

Quando da primeira gestão da prefeita Teresa Surita (1993-1996), a cidade era constituída por 32 bairros. Observando a malha urbana desse período, vê-se que já ocorria a expansão para o setor Oeste, mais carente de infraestrutura, equipamentos e serviços quando se comparava com a qualidade dos serviços concentrados na área central da cidade. Seguindo os rumos do planejamento urbano de várias cidades brasileiras, nessa primeira gestão, Teresa Surita deu início à elaboração de um novo plano, agora concebido como estratégico, cujo objetivo era a melhoria das condições da infraestrutura física da cidade, embora ainda vigorasse o Plano Diretor Urbano existente, elaborado na gestão anterior.

Esse processo de urbanização promoveu o embelezamento urbanístico não apenas das áreas centrais, mas também das periféricas, contribuindo para que ocorresse a especulação imobiliária nas áreas circunvizinhas de alguns bairros periféricos, por meio de loteamentos. As ações visavam ao embelezamento das vias públicas, com a construção de praças e calçadas, ações que modificaram a paisagem urbana da cidade, por exemplo, igarapés foram canalizados e deram lugar a praças (Figura 5). 


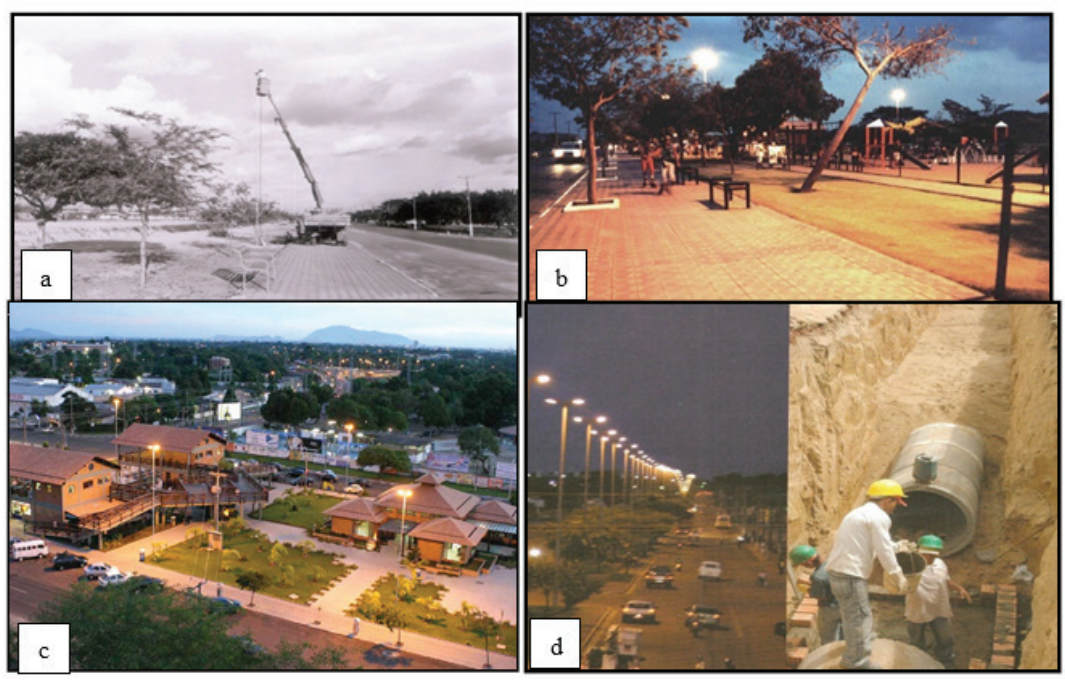

Figura 5 - Ações de urbanização da cidade

Fonte: (a) Veras (2009)/(b) Batista (2013) /(c) Orihuela (2006)/ (d) Teresa (2012).

As ações da prefeitura para a melhoria urbanística representavam uma forma de a gestão pública promover o desenvolvimento econômico e social, buscando atrair investimentos privados, principalmente do setor turístico e comercial.

Essa política pública redistributiva visa ao maior controle do espaço territorial por meio da intervenção estatal na gestão e no planejamento e revela que a produção estava estritamente relacionada com a promoção do espaço urbano, mas promovendo a divisão social e fazendo surgir bairros destinados a trabalhadores assalariados.

Ottomar de Souza Pinto, doravante Ottomar Pinto, esteve à frente da administração municipal no período de 1997 a 2000 e adotou a mesma política de quando foi governador de Roraima, desenvolvendo políticas de governo consubstanciadas no assistencialismo, no incrementalismo e na baixa preocupação com o planejamento urbano dentro das diretrizes nacionais da política urbana.

Mantendo-se fiel ao modelo populista, continuou a política de doações de lotes urbanos, com incentivo a ocupações irregulares. Essas ocupações ocorriam em áreas de proteção ambiental, principalmente no setor Oeste. A ocupação de áreas urbanas não prosseguia na mesma 
velocidade da urbanização. Essa prática era justificada pela tática de ocupar para depois urbanizar. Em sua gestão de 1991-2000, a população de Boa Vista teve uma taxa média de crescimento anual de 4,35\%, passando de 138.687 em 1991 para 200.568 em 2000. A taxa de urbanização cresceu 25,92\%, passando de 78,04 em 1991 para 98,27\% em 2000 (COHERE, 2005-2006, p. 23).

Essa expansão aumentou ainda mais a necessidade de equipamentos urbanos e infraestrutura física e social, a qual deveria ser prevista quando dos incentivos de ocupação desses novos bairros, mas, no entanto, não foi o que gerava a precariedade desses serviços. Se, de um lado, as políticas de doações de lotes expandiam a cidade, por outro lado, faltavam políticas que direcionassem esse crescimento de modo mais apropriado.

Ottomar Pinto deu início a uma série de ações de incentivo à ocupação em áreas periféricas. Cabe destacar que essas ocupações não obedeciam a critérios técnicos que direcionassem tais processos, mas apenas sociais, como necessidade de habitação, e mantinham formas de segregação.

Para Trindade Jr. (1997, p.17), “a segregação imposta engendra áreas residenciais dos grupos sociais de renda mais baixa [...] cujas opções de como e onde morar são [...] nulas, restando aceitar os espaços que lhe são reservados”, o que resulta em ocupações em áreas desfavoráveis e distantes do centro.

Ottomar Pinto, dando continuidade às ações de urbanização e revitalização, instituiu a Lei $\mathrm{n}^{\circ} 483$, de 9 de dezembro de 1999, a qual altera dispositivos que tratam da promoção do desenvolvimento urbano, zoneamento, uso e ocupação, redefinindo o limite de alguns bairros e acrescentando outros. Boa Vista passa a ter novos limites entre bairros.

Esse fato contribui para a consolidação da segregação espacial urbana, que faz com que as populações de baixa e média renda sejam impelidas para áreas periféricas pouco privilegiadas e quase sempre sem os equipamentos urbanos ideais para uma boa qualidade de vida, ou ainda com baixa infraestrutura física e social.

Em 2001, deu-se início à segunda gestão de Teresa Surita, cuja plataforma eleitoral garantia a continuação das obras urbanas desenvolvidas na sua primeira gestão e a ampliação dos projetos sociais. Implantou o programa Braços Abertos, que tinha como objetivo urbanizar bairros da cidade carentes de infraestrutura física e urbana. 
Essa modernização da cidade, presente nos discursos e nas propostas políticos ocorridos no Brasil a partir de 2001, favorecia a mercantilização do planejamento, reforçando a ideologia de que modernidade é sinônimo de garantias sociais (Maricato, 2011; Souza, 2006).

O programa Braços Abertos objetivava implantar a administração participativa e modernizar Boa Vista. Esse programa realizou um diagnóstico técnico. Foi realizada uma licitação, cuja empresa vencedora foi a Diagonal Urbana Consultoria S/C Ltda, com sede em São Paulo, e o custo dessa atividade foi de $\mathrm{R} \$ 1.523 .000,00$ (Salgado, 2003).

$\mathrm{O}$ crescimento da malha urbana em direção à periferia originada pelo fechamento dos garimpos, o empobrecimento da população em consequência da escassez de empregos, a gratuidade de alguns espaços que os governantes estadual e municipal disponibilizavam à população e ainda a especulação urbana surgida em áreas próximas aos lotes distribuídos e aos conjuntos populares (Diagonal Urbana Consultoria S/C Ltda, 2001; Boa Vista, 2002). Esses fatores, identificados no diagnóstico, demonstravam a necessidade de políticas públicas e um planejamento urbano que pudessem responder com eficácia aos problemas de alagamento, coleta de lixo e pavimentação e que aproximassem a gestão municipal da real necessidade da população, produzindo melhorias quanto a habitação, transporte, lazer, saúde, segurança e educação.

Diante dessa situação, foram realizadas diversas audiências públicas, reuniões técnicas e grupos de estudos, com as comunidades dos bairros e instituições públicas, como forma de introduzir a gestão participativa. Essas políticas de modernização das cidades favoreciam grandes grupos empresariais do ramo da construção civil, que tinham nas obras públicas um campo para a comercialização de seus produtos. Aos governos, significavam uma alternativa para a geração de emprego e renda.

O programa visava às condições materiais que permitiam a produção e a reprodução do capital e do espaço, favorecendo o empresariamento urbano, o que, segundo Havery (2012), requer abertura de espaço para novos empreendimentos imobiliários, clima para negociações, estratégias de valorização imobiliária, marketing urbano. Táticas estas com vistas à arrecadação tributária e à venda da cidade.

A ação da prefeitura procurava contornar os problemas produzidos pelas ocupações irregulares, por meio de investimento na estruturação 
urbana. Essa estratégia era uma alternativa à circulação de capitais. Tais mudanças representam o esgarçamento do tecido urbano, devido ao descumprimento das orientações legais.

Em 2005, retorna ao governo municipal Teresa Surita. Nesse período, foram implantadas ações de renovação urbana que ocasionaram uma série de ressignificações dos espaços públicos, como foi o Centro Histórico, no sentido da valorização turística da cidade. Essas estratégias se propunham produzir um marketing urbano e promover o desenvolvimento comercial, como foi o caso da Orla Taumanan (Figura 6).

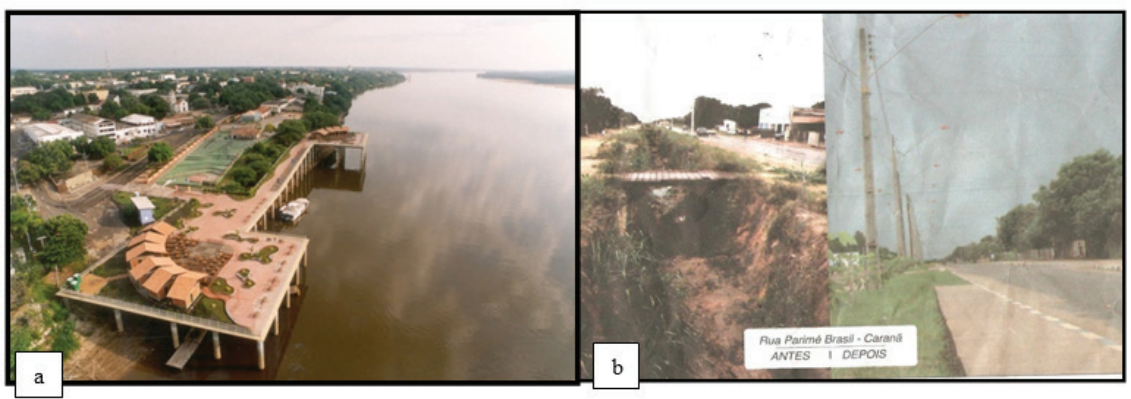

Figura 6 - Orla Taumanan (2008) e obras de infraestrutura na zona Oeste (2001-2006) Fonte: (a) Orihuela (2008)/ (b) Jornal Agora é 15 (2012).

As alterações espaciais estabeleceram novas relações sociais entre homem e espaço, como valorização imobiliária, fuga de moradores para outros espaços, especulação imobiliária por parte de agentes imobiliários privados e particulares, que viam nessa atividade uma forma de geração de renda, bem como novos usos destes espaços.

As ações desenvolvidas nessa gestão ainda não se balizavam por um Plano Diretor definitivo ou mesmo um planejamento capaz de atender às necessidades do crescimento urbano. Fato que, segundo Veras (2011, p. 97), contribuía para a "precarização das condições de vida de parcelas significativas da população urbana".

Em 28 de novembro de 2006, foi promulgada a Lei Complementar no 924, que instituía o novo Plano Diretor. Nesse novo cenário, o Plano Diretor aparece como instrumento fundamental, sob a ideia que a "[...] autonomia para a escolha [...] que melhor atenda ao seu desenvolvimento urbano [...] deve estar em consonância com a realidade urbana de cada 
cidade, garantindo que o plano trace corretamente suas estratégias de planejamento" (Mancini, 2009, p. 46).

O novo Plano Diretor, segundo a Rede de Avaliação e Capacitação para a Implementação dos Planos Diretores Participativos do Ministério das Cidades, da forma como foram conduzidos os trabalhos de sua elaboração, dissolvia o envolvimento da participação popular. O plano “[...] não apresenta uma preocupação sistemática com a moradia popular e com o acesso a terra urbanizada para habitação de interesse social. [...] o plano prevê apenas programas de regularização fundiária, em que o foco é apenas 'remediar' o que já foi produzido" (Brasil, 2007, p. 14).

Segundo o diagnóstico, a estrutura urbana de Boa Vista apresenta elevada segregação espacial, decorrente da implantação de conjuntos habitacionais e loteamentos sem planejamento, que induziram a expansão para áreas ambientalmente frágeis e, portanto, inadequadas para a ocupação (Brasil, 2007). Aponta ainda uma concentração acentuada de equipamentos urbanos na área central da cidade, o que indica que a acessibilidade a serviços essenciais para os moradores de regiões periféricas é ruim.

Iradilson Sampaio de Souza, doravante Iradilson Sampaio, assumiu a prefeitura de Boa Vista no dia 31 de março de 2006, após Teresa Surita ter renunciado ao cargo para se candidatar ao Senado Federal. Foi reeleito nas eleições de 2008. O carro-chefe da sua política pautava-se na implantação da área e da zona de livre comércio, que mobilizariam o crescimento econômico, favorecendo a sustentabilidade econômica do município a partir da implantação de indústria e de investimentos comerciais.

Durante o período em que esteve na gestão municipal, Iradilson Sampaio buscou dar continuidade aos compromissos de campanha, como foi o caso da criação, dentro da estrutura da Zona de Processamento de Exportação (ZPE), da Área de Livre Comércio (ALC) e do abatedouro para animais de pequeno porte, além da Central de Abastecimento de Produtos Agroflorestais e Extrativistas de Boa Vista (CEASA).

Esses projetos direcionados pelas políticas do governo de Teresa Surita, em sua maioria a partir de convênios e recursos advindos da Caixa Econômica Federal e do Ministério das Cidades, foram fundamentais para a implantação de ações como a rede de saneamento básico e pavimentação de ruas em áreas tradicionais do setor Oeste da cidade. 
Observa-se que, nessa nova configuração urbana de Boa Vista, os bairros passam a se direcionar ainda mais para o setor Oeste, em áreas de alagamentos e próximas a nascentes de igarapés e do anel viário. Juntamente com eles, conjuntos de moradia popular, subsidiados pelo projeto Morar Bem e Minha Casa, Minha Vida, para atender uma população urbana que cresceu, segundo dados do IBGE (2011), de 246.732 em 2000 para 344.859 em 2010.

Consideramos, como Silva (2007a), que o espaço é um produto social de representações e temporalidades pelas quais o urbano, o conteúdo, assume a qualidade de força que determina a maneira de se conceber os lugares e como o representamos. Por exemplo, um rio, que em um período tem uma larga função, em outro, é visto como algo secundário. Assim, a expansão urbana, ao ser produzida, modifica o conteúdo, a forma e a função dos lugares.

Nas políticas habitacionais, Iradilson Sampaio, dentro das estratégias nacionais de construção de casas populares, fomentadas pelo projeto Minha Casa, Minha Vida, por meio de convênio entre a Caixa Econômica Federal e a prefeitura, implantou dois conjuntos de residência. Mancini (2009, p. 65) afirma que "muitos destes projetos e ações foram instalados em áreas irregulares, em lotes públicos ou privados e ainda sem condições adequadas de infraestrutura e transportes, ou em áreas de risco ambiental".

\section{Considerações finais}

Em Boa Vista - RR, conforme a escala temporal utilizada nesse diálogo com o político e urbano, percebe-se que a transformação do território em estado, ocorrida em 1988, promoveu a transferência de infraestrutura de poder para a referida capital, que, na verdade, já vinha exercendo desde os idos coloniais a centralidade loco-regional.

Assim, a capital que nascia herdou a burocracia pública preexistente da época da administração territorial, o modelo centralista e autoritário das políticas públicas constituídas historicamente no Brasil e os paradigmas urbanísticos de influência norte-americana e europeia. Aspectos pautados na tendência liberal e neoliberal, porém, com forte presença da ação estatal. 
A suposta modernidade foi uma ideologia ao longo dos tempos disseminada pelo governo e por tecnocratas, que a utilizaram como elemento para justificar a implantação de megaprojetos arquitetônicos, redefinição espacial, empreendimentos culturais, marketing urbano e fragmentação do tecido urbano. Essas ações tinham aval do Estado e, na sua maioria, foram idealizadas para atender à produção do capital, ou seja, potencializar o comércio com vistas a aumentar a arrecadação tributária.

Pode-se considerar que essa falta ou não de planejamento, que ganha reforço por meio de ações incrementais, germe que corrói e esgarça o tecido urbano, perceptível na estrutura urbana de Boa Vista, historicamente revela os desastrosos modelos impostos pelo planejamento urbano brasileiro, que foram ora guiados pelas concepções liberais e neoliberais, ora pelo intervencionismo estatal.

Contudo, no conjunto das gestões desde 1988, em termos de expansão urbana, o crescimento desordenado contribuiu para que os serviços urbanos disponíveis apresentassem descompasso com o acelerado crescimento populacional.

Esse descompasso foi resultado de ocupações irregulares em áreas impróprias, doação de lotes sem titularidade, formação de bairros sem nenhuma condição social, com falta de saneamento básico, ruas sem pavimentação, sistema de transporte, comunicação e iluminação pública e água encanada insuficiente e que demonstravam déficit habitacional. Essas ocupações revelam a não obediência aos instrumentos de gestão pública, como Plano Diretor, Código de Postura e Código Florestal, e às diretrizes gerais, como a Constituição Federal e o Estatuto da Cidade.

Ainda no tocante à produção do espaço no período posterior à criação do estado de Roraima, pode-se verificar que, a partir de 1993, houve forte ação da administração pública na estruturação urbana por meio de edificações de prédios públicos e na implementação de infraestrutura física e social, que estimularam a formação de novos bairros e a expansão de outros, modelo que continuou a ser reproduzido nos anos que se seguiram à criação do estado.

Esses aspectos possibilitaram às gestões municipais atuarem mais direcionadas pelas políticas de governo do que pelas políticas públicas, utilizando-se do poder para fins eleitoreiros. É importante compreender que os paradigmas da modernidade, do desenvolvimento sustentável e do marketing urbano, que foram sendo introduzidos no espaço urbano de Boa 
Vista, contribuíram para uma nova morfologia urbana, que não evidencia necessariamente um planejamento. Em decorrência disso, foram formados novos centros comerciais em outras áreas distantes da área central da cidade, porém, sem as mesmas condições do centro.

O processo de produção socioespacial de Boa Vista constitui-se de manifestações de jogos de interesses políticos, econômicos e sociais, pelos quais se definiu a organização do urbano. Nessa dinâmica, os espaços foram produzidos e receberam novos conteúdos e funcionalidades, mudanças estas que foram se desenvolvendo segundo os interesses do capital e de determinadas condições sociais presentes em sua organização espacial.

O processo de produção do espaço urbano de Boa Vista está vinculado a diferentes agentes produtores do urbano, que, segundo seus interesses, contribuíram para uma produção desigual do espaço, o que convida a refletir sobre o espaço ainda ser um campo de relação de poder e sobre a necessidade do uso do conhecimento e do saber científico para que o espaço, no caso, o urbano seja produzido por meio de planejamento que consiga superar as dificuldades erguidas ao longo da história, através de políticas públicas que venham atender às exigências do cidadão e não simplesmente do mercado.

Mas, para isso, é necessário entender a produção do espaço como resultado de um processo de acumulação capitalista, no qual o Estado é o principal agente de produção e as políticas públicas por ele conduzidas são, de certa forma, causadoras da diferenciação do espaço urbano. Essas mesmas políticas terminam por contribuir para a exclusão social e a inobservância de elementos técnicos, científicos, sociais e econômicos na produção do espaço.

\section{Referências}

BARBOSA, I. R. Ocupação humana em Roraima I. Do colonialismo ao início do assentamento dirigido. Boletim do Museu Paraense Emilio Goeldi, v. 9, n. 1, 1993.

Ocupação humana em Roraima II. Uma revisão do equívoco da recente política de desenvolvimento e o crescimento desordenado. Boletim do Museu Paraense Emilio Goeldi, v. 9, n. 2, 1993a.

BARROS, N. C. C. Paisagem e tempo na Amazônia Setentrional: estudo de ocupação Pioneira na América do Sul. Recife: Ed. Universitária da UFPE,1995. 
BATISTA, A. N. Políticas públicas e produção do espaço urbano de Boa Vista - Roraima (1988-2011). 2013. Dissertação (Mestrado) - Programa de PósGraduação em Geografia da Universidade Federal de Roraima, Boa Vista, 2013.

BECKER, B. K. Amazônia. 6. ed. São Paulo: Ática, 1998.

BONATTO, F. Transformações na paisagem natural de Boa Vista - RR: Um diagnóstico ambiental por geoprocessamento. 2002. 346p. Dissertação (Mestrado) - Universidade Federal do Rio de Janeiro, Rio de Janeiro, 2002.

BRASIL. O espaço urbano: novos escritos sobre a cidade. São Paulo: Labur Edições, 2007. 123 p. Disponível em <http://www.fflch.usp.br/dg/gesp.pdf>. Acesso em; 15 nov. 2012.

COHERE. Centro Pelo Direito à Moradia Contra Despejos. Conflitos urbanoambientais em capitais amazônicas: Boa Vista, Belém, Macapá e Manaus. Imprensa Gráfica Calábria, Embaixada da Holanda no Brasil, 2006, 93p.

CORRÊA, R. L. O espaço urbano. São Paulo: Ática, 2000.

DIAGONAL URBANA CONSULTORIA S/C LTDA. Prefeitura Municipal de Boas Vista, Concorrência 10/02 (parte 1/2). Proposta Técnica, São Paulo, 2001. Editado em Boa Vista, 2002.

FREITAS, A. Geografia e história de Roraima. 5. ed. rev. atual. Manaus: Belvedere, 1997.

HARVEY, David. O direito à cidade. Lutas Sociais, São Paulo, n.29, p.73-89, jul./ dez. 2012.

GOTTDIENER M. A produção social do espaço urbano. São Paulo: Editora da Universidade de São Paulo, 1993.

HUERTAS, D. M. Da fachada atlântica à imensidão amazônica: fronteira agrícola e integração territorial. São Paulo: FAPESP, 2009.

IBGE. Instituto Brasileiro de Geografia e Estatística. Censo demográfico 2010. Brasil, 2011. Disponível em: <https:/ww2.ibge.gov.br/home/estatistica/ populacao/censo2010/default.shtm>. Acesso em: 26 mar. 2018.

JORNAL AGORA É 15. Boa Vista, 2 ago. 2012.

LUCKMANN, D. História e geografia do município de Boa Vista. Boa Vista: Prefeitura Municipal de Boa Vista/Fundação de Educação, Ciências e Cultura de Roraima,1989. (Série: Roraima através dos municípios; Volume 1).

MANCINI, E. L. A R. Avaliação política do Plano Municipal de Habitação em Boa Vista: a habitação de interesse social. 2009. 131p. Dissertação (Mestrado) Universidade Federal do Maranhão, São Luís, 2009.

MARICATO, E. Brasil, cidades: alternativas para a crise urbana. Petrópolis: Vozes, 2011.

. Reforma urbana: limites e possibilidades. Uma trajetória incompleta. In: RIBEIRO, L.C de Q; SANTOS JUNIOR, O. A. dos (Org.). Globalização, fragmentação e reforma urbana: o futuro das cidades brasileiras na crise. Rio de Janeiro: Civilização Brasileira, 1997. 
ORIHUELA, T. Fotos Boa Vista (cidade). Disponível em: <https://www. panoramio.com/user/949380>. Acesso em: 10 mar. 2012.

REVISTA É AGORA. Nova força para Roraima. Revista de campanha de Teresa Jucá para o Senado, 2006.

RICE, A. H. Exploração na Guiana Brasileira (1924-1925). Tradução e notas de Lacyr Schettino. São Paulo: Editora da Universidade de São Paulo, 1978.

Projeto Crescer Boa Vista - Roraima. In: TEIXEIRA, M. A. C.; GODOY, M. G. de; COELHO, C. Experiências de gestão pública e cidadania - ciclo de premiação 2004. São Paulo: Programa Gestão Pública e Cidadania, 2004.

SALGADO, Sílvia Regina Costa. Programa Braços Abertos, In: LOTTA, G.S. et al (Org.) 20 experiências de gestão pública e cidadania. São Paulo: FGV, 2003. (Programa Gestão Pública e Cidadania, 2002).

SANTOS, M. A natureza do espaço: técnica e tempo, razão e emoção. São Paulo: EDUSP, 2002.

SILVA, José Borzacchiello da. Dez anos de Estatuto da Cidade. Estatuto da Cidade. Brasília: Senado Federal, 2011. p. 22.

. Planejamento urbano e crise das cidades. Terra Livre, Presidente Prudente, ano 24, v. 1, n. 30, p. 83-96, jan./jun. 2008.

Diferenciação socioespacial. Revista Cientifica Cidades, v. 4, n. 6, Presidente Prudente, 2007a.

SILVA, P. R. de F. Dinâmica territorial urbana em Roraima - Brasil. 2007. 329p. Tese (Doutorado) - Programa de Pós-Graduação em Geografia Humana, Universidade de São Paulo, 2007.

SOUZA. M. L. de. Mudar a cidade: uma introdução crítica ao planejamento e à gestão urbanos. Rio de Janeiro: Bertrand Brasil, 2006.

SOUZA, M. L.; RODRIGUES, G. B. Planejamento urbano e ativismos sociais. São Paulo: UNESP, 2004.

SURITA, T. Ela sabe trabalhar. Boa Vista, 2012.

TERRITÓRIO FEDERAL DE RORAIMA. Secretaria de Educação e Cultura. Série Monográfica do Município de Boa Vista. Boa Vista: Secretaria de Educação e Cultura; Departamento de Assuntos Culturais; Divisão de Ensino Superior, 1987.

TRINDADE JR., S. C. da. Produção do espaço e uso do solo urbano em Belém. Belém: UFPA/NAEA/PLADES, 1997.

VERAS, A. T. de R. A criação de Roraima e sua importância na dinâmica da cidade de Boa Vista. In: OLIVEIRA, Rafael da Silva; COSTA, Everaldo Batista. As cidades entre "real" e o imaginário Estatuto no Brasil. São Paulo: Expressão Popular, 2011.

. A produção do espaço urbano de Boa Vista Roraima. 2009. 235 f. Tese (Doutorado) - Programa de Pós-Graduação em Geografia Humana, Universidade de São Paulo, 2009.

VILLAÇA, F. Espaço intra-urbano no Brasil. São Paulo: FAPESP, 2003. 
Amarildo Nogueira Batista - Licenciado em História pela Universidade Federal de Roraima e bacharel em Ciências Sociais pela Universidade Federal de Roraima. Foi doutorando do Programa de Pós-Graduação em Geografia da Universidade Federal do Ceará e professor da Universidade Estadual de Roraima.

José Borzacchiello da Silva - Licenciado em Geografia pela Universidade do Rio de Janeiro, mestrado e doutorado em Geografia pela Universidade de São Paulo e pós-doutorado em Geografia pela Université de Paris IV. Atualmente é professor emérito da Universidade Federal do Ceará. ORCID: https://orcid.org/0000-0001-7367-0302.

Recebido para publicação em 20 de novembro de 2017 Aceito para publicação em 03 de janeiro de 2018 